phone diaries to capture contextual features of STI/HIV-risk that could impact disease acquisition among female sex workers (FSW).

Methods Women engaging in transactional sex in the prior 90 days were recruited utilising incentivized snowball sampling. Participants completed STI testing and baseline/exit surveys. Over 4 -weeks, they completed twice-daily electronic diaries assessing event-level sexual behaviour, condom use, and drug use. Weekly inperson interviews used open-ended questions to explore geographical characteristics of sexual encounter locations as well as acceptability of event-level monitoring.

Results $25 / 26$ participants (median age 43.5 years) completed the 4 -week study. At baseline, $27 \%$ tested positive for a STI. Participants completed $84.5 \%$ of 1,518 expected surveys and $95 \%$ of 106 expected interviews. Patterns of diary compliance were stable over time. Partnered sexual activity was captured in $21.4 \%$ of diaries. At the participant-level, most reported giving oral sex $(84.7 \%)$ or vaginal sex (96.1\%); fewer (19.2\%) reported engaging in anal sex. Among women reporting partnered sexual behaviour with any partner type (i.e., new/regular customers, romantic partners), using condoms was reported $39.2 \%, 45.5 \%$ and $83.3 \%$ of the time for giving oral sex, vaginal sex, and anal sex respectively. At the event-level, the frequency of giving oral sex, vaginal sex or anal sex did not significantly change over time.

Conclusions It is feasible to engage and retain FSW in a technologically-advanced study to characterise risk contexts of sexual events. Adherence to study protocol was high indicating event-level monitoring using cell phone based diaries is acceptable. These data can be utilised to improve our understanding of the individual, relational and environmental factors that influence STI/HIV acquisition among FSW.

\section{P4.038 AN ENVIRONMENTAL AND POLITICAL ECONOMIC PERSPECTIVE ON SEXUAL RISK: TEAHOUSES, FEMALE SEX WORK AND PEER ETHNOGRAPHY IN ZIGONG, SOUTH WEST CHINA}

doi:10.1136/sextrans-2013-051184.0936

${ }^{1}$ R Lorway, ${ }^{2} \mathrm{~J}$ Zhang, ${ }^{2} \mathrm{X} \mathrm{Ma},{ }^{3} \mathrm{O} \mathrm{Li},{ }^{3} Y \mathrm{Xie},{ }^{1} \mathrm{~S}$ Khan, ${ }^{1} \mathrm{~J} \mathrm{~F}$ Blanchard, ${ }^{1 B} \mathrm{~B}$ Y. ${ }^{1}$ University of Manitoba, Winnipeg, MB, Canada; ${ }^{2}$ Sichuan University, Chengdu, China; ${ }^{3}$ Zigong Center for Disease Control and Prevention, Zigong, China

Background In Sichuan province, the criminalised status of female sex work, coupled with the mobility of female sex workers (FSWs), poses major challenges to gathering information about the organisation of the sex trade.

Objectives This study has 2 main objectives: (1) To document the environmental risk factors in sex work venues; (2) To describe the sex trade industry in relation to political economic factors, including broader economic transformations.

Methods We trained 3 FSWs to conduct participant observation and ethnographic field note writing, including "thick descriptions" (the pealing back of multiple layers of meaning during observations of social scenes). These observations were conducted in 9 sex work venues representing previously mapped FSW venues. Findings were contextualised with secondary historical sources.

Findings Participant observation revealed that FSWs were independent when choosing where they worked and when they shifted to another work site. However, gender power inequalities between sex workers and their clients were also described. These power relationships are tied to structural factors that converge in small urban spaces. Teahouses, for example, have a long history that brings together entertainment, leisure, business and politics. In recent decades, there has been a resurgence of leisure and entertainment venues in Sichuan province in the Dengist era of economic liberalisation. Teahouses, are therefore part of a wider proliferation of small leisure spaces in urban milieus that allow (mostly) men from a variety of backgrounds to enjoy pleasure and "recapture" ideas of freedom that were suppressed under the Maoist regime. For women working in these spaces, however, the unequal social relations they encounter reflect the limited opportunities that women more generally encounter in post-socialist China.

Conclusion Any intervention that seeks to reduce risk behaviours in sex work venues must account for how sexual risk practises and vulnerabilities are rooted in larger political economic realities.

\section{P4.039 HIV-POSITIVE CLIENT REPRODUCTIVE DESIRES AND HEALTH CARE PROVIDER PERSPECTIVES OF PREGNANCY IN HIV-POSITIVE WOMEN IN ETHEKWINI DISTRICT, KWAZULU-NATAL, SOUTH AFRICA}

doi:10.1136/sextrans-2013-051184.0937

C Milford, R Greener, J Pienaar, M Beksinska, L Rambally, M Drace, K Sithole, Z Mabude, J Smit. MatCH (Maternal, Adolescent \& Child Health), University of the Witwatersrand, Overport, Durban, South Africa

Background The Province of KwaZulu-Natal, South Africa has among the highest concentrations of people living with HIV However, with improved access to ARVs and PMTCT, PLWHIV are now able to have children with minimal risk. There is therefore a need to explore current fertility and contraceptive desires of this population to ensure appropriate and accessible sexual and reproductive health (SRH) counselling.

Methods Baseline and Endline surveys were conducted in 2009 and 2011 with providers and clients at seven healthcare facilities, before and after the implementation of a SRH service integration model, in eThekwini District. HIV-positive clients' fertility intentions, contraceptive use and providers' perceptions of pregnancies among HIV-positive women were explored. Descriptive statistics were generated using SPSS.

Results At baseline 46 providers and 86 HIV-positive clients (14 male, 72 female) and at endline 44 providers and 144 HIV-positive clients (43 male, 101 female) were interviewed. $18.6 \%$ and $38 \%$ of clients at baseline and endline, respectively, wanted more children. At baseline and endline, females with HIV-positive partners were less likely than those with HIV-negative partners to want more children. Concerns about the health of the baby and self were common reasons for not wanting more children. At baseline, of those who wanted children, half the women and all men were using contraception. At endline, $80 \%$ of women and $72 \%$ of men who wanted children were using contraception. Male condoms were the most common contraceptive used. At baseline, $43 \%$ of providers thought healthy HIV-positive women could consider having children, compared with $66 \%$ at endline.

Conclusion There is a need for reproductive choices and family planning to be integrated with HIV services. Comprehensive policies and programmes should be developed to address SRH counselling needs of HIV-positive men and women, and address the values and training needs of providers.

\section{P4.040 STUDY TO EXPLORE THE SEXUAL BEHAVIOUR AND PRACTISES, AND DRUG USE PATTERN AMONG FEMALE INJECTING DRUG USERS IN SIKKIM}

doi:10.1136/sextrans-2013-051184.0938

R Basu, N Panda, A RoyChowdhury, R Kr Sonkar, S Das Konar, S Chowdhury, M Kundu, R Das. CINI, Kolkata, India

Background North East of India is a hub of Drug Use activities (NACO 2007). Although the government has specific programme to reduce the risks and vulnerabilities of Injecting Drug Users and cater to their health needs, it focuses on the male IDUs, ignoring the vulnerabilities of Female Injecting Drug Users; not recognising their 
separate needs. There is no Gender disaggregated data on IDUs available (UNODC 2004). Given that the socio-economic background and psychological conditions of FIDUs are different from their male counterparts (UNODC 2004), this study has been undertaken to study the sexual practises of and drug use pattern among FIDUs in Sikkim.

Methods The study has been conducted among FIDUs registered under the government projects operational in Sikkim. The sample had been selected on the basis of stratified random sampling. Structured Questionnaires had been developed and the Interviewers had been oriented on the research tool.

Results The study reveals that $73 \%$ of the FIDUs are sex workers, while $27 \%$ have multiple sexual partners. $36 \%$ inject drugs alone (70\% have suffered overdose) while $64 \%$ inject drugs in groups. $80 \%$ of the respondents consume both injecting and non-injecting drugs. $39 \%$ are daily drug users and the rest weekly. $38 \%$ and $42 \%$ are using drugs since for last 6 months and over one year respectively, highlighting that drug use is an age old practise and there are continuous new entries. Although only $10 \%$ of the respondents use condoms, $89 \%$ use oral contraceptives thereby reducing chances of pregnancy but risk of STI and HIV remain. $57 \%$ of the respondents have suffered from STI.

Conclusion Thus, the study reveals that convergence of drugs related services and sexual \& reproductive health services are essential. Unsafe injecting drug use combined with unprotected sex with multiple partners needs to be recognised and addressed through a comprehensive programme.

\section{P4.041 FACTORS ASSOCIATED WITH FREQUENT ALCOHOL DRINKING AMONG MEN WHO HAVE SEX WITH MEN: FINDINGS FROM A MULTI-SITE BIO-BEHAVIOURAL SURVEY IN INDIA}

doi:10.1136/sextrans-2013-051184.0939

'D Yadav, ${ }^{2 V}$ Chakrapani, 'P Goswami, 'S Ramanathan, 'L Ramakrishnan, 'B George, 'S Sen, ${ }^{3} \mathrm{R}$ Paranjape. ${ }^{1} \mathrm{FHI}$ 360, New Delhi, India; ${ }^{2}$ Centre for Sexuality and Health Research and Policy (C-SHaRP), Chennai, India; ${ }^{3}$ National AIDS Research Institute (NARI), Pune, India

Background Men who have sex with men (MSM) in India are mostat-risk of HIV infection, with HIV prevalence almost 20 times higher than that in the general population. We describe the relationship between frequency of alcohol use and HIV-related risk behaviours among Indian MSM to develop strategies for addressing alcohol use within HIV interventions.

Methods Data for this analysis were drawn from a cross-sectional bio-behavioural survey (2009-2010) conducted in the states of Maharashtra, Tamil Nadu and Andhra Pradesh. 3,880 MSM were recruited from cruising sites using time-location cluster sampling. Binary logistic regression was carried out to assess relationships between frequent alcohol use and other sexual risk behaviours

Results We categorised those who reported consuming alcohol daily or at least once a week as 'frequent' drinkers ( $40 \%$ of the sample) and the remaining as 'infrequent' drinkers. Among frequent drinkers, majority were above 24 years (66\%), literate (85\%), self-identified as Kothis[feminine and receptive partner] (53\%), had paying male partners $(65 \%)$ and were exposed to HIV prevention interventions (78\%). Multivariate analysis showed that frequent alcohol drinkers were more likely to be above 24 years (adjusted odds ratio [AOR] 1.37, p < 0.05) and employed (AOR $1.54, \mathrm{p}<0.05)$. Frequent alcohol drinkers were less likely than infrequent drinkers to report consistent condom use with paying male partners (AOR 0.75, p < 0.05), consistent condom use with regular male partner (AOR 0.74, $p<0.05$ ), being community group member (AOR 0.84, p < 0.05), and self-identified as Kothi MSM (AOR 0.75, p < 0.05)
Conclusions Frequent alcohol drinking was more common among kothi-identified MSM and was significantly associated with inconsistent condom use with paying male partners and regular male partners. HIV prevention programmes need to be address alcohol consumption with better systematic screening counselling and referral to dependence treatment programme for men who have sex with men in India.

\section{P4.042 IGNORANCE! MAJOR CAUSE OF ADVANCED FORM OF GENITAL WARTS CLINICAL PRESENTATION IN KUMASI GHANA}

doi:10.1136/sextrans-2013-051184.0940

${ }^{1}$ T Agyarko-Poku, ${ }^{2} Y$ Adu Sarkodie, ${ }^{3} \mathrm{~L}$ Atakorah-Yeboah. 'Suntreso Government Hospital, Ghana Health Services, Kumasi, Ghana; ${ }^{2}$ School of Medical Sciences, Kwame Nkrumah University of Science and Technology, Kumasi, Ghana; ${ }^{3}$ Catholic University College, Fiapre, Sunyani, Ghana

Background Genital Wart is the most common clinical manifestation of genital Human papilloma virus infection. Early reporting of genital warts is the key to successful management. Presentation of more cases of an advanced form of genital warts to at Suntreso Sexually Transmitted Infection (STI) Clinic in Kumasi Ghana prompted this study to determine the possible reasons for the late reportage of genital warts conditions.

Methods 431 patients made up of $55.5 \%$ (239/431) females (F) and $44.5 \%(192 / 431)$ Males (M) who reported with an advanced form of genital warts- defined as warts affected more than one third of the external genital namely, vulva, vagina, peri-anal, penis and scrotum areas, with or without ulcerations- who consented to participate, were recruited for the cross sectional study. Participants were interviewed using structured questionnaire. Socoidemographic information was gathered. Data was analysed using SPSS 16.

Results $7.5 \%$ correctly mentioned that its genital warts (32/431; M- 9.9\%,19/192: F- 5.4\%). 46.1\% identified their condition as rashes (M-44.8\%, F- 46.4\%), $11.9 \%$ as said its cancer (M- 7.8\%, F-15.1), $14.6 \%$ as swelling (M-12.0\%,F- $16.7 \%$ ) while $19.9 \%$ had no idea about what is happening to their body (M-12.5\%, F- 25.5\%). Of the 42 respondents who have had tertiary education only $5(11.7 \%)$ could identify correctly genital warts.

Conclusion Very few people could identify genital warts showing a deficit in knowledge on genital warts among the population. The situation is not limited to only people with no formal education. Lack of knowledge on genital wart may be a precipitating factor in the delay reportage of cases. How patients perceived the causes of their conditions determines where and when to seek medical care in the era of medical plurarism. There is the need to step up education on genital warts among the population in Ghana.

\section{P4.043 THE MULTI-COMPONENT STUDY OF LOCATIONS, ESTIMATION SIZE AND BEHAVIOUR OF YOUNG HIGH RISK GROUPS IN ZAPORIZHZHIA CITY (UKRAINE) FOR DEVELOPMENT OF FOCUS INTERVENTION MODEL}

\section{doi:10.1136/sextrans-2013-051184.0941}

D Pavlova, Olga Balaireva, Tatiana Bondar, lana Sazonova, Olena Sakovych, Marissa Becker, Rob Lorway, S Isac. Ukrainian Institute for Social Research after Olexander Yaremenko, Kyiv, Ukraine

Background Ukraine's HIV prevalence is estimated at $1.6 \%$ of adult population. HIV epidemic in Zaporizhzhia is not extensive but tends to grow. The lack of knowledge about underage RG size is essential barrier for programme planning and service provision.

Methodology Team conducted multi-component research aimed at finding locations, size, typology and behaviour of risk groups aged 14-25. (i.e., FSWs, IDUs and street based children (SBC)). The 